\title{
Knock-down of PSAT1 Enhances Sensitivity of NSCLC Cells to Glutamine-limiting Conditions
}

\author{
HYEON-OK JIN ${ }^{1}$, SUNG-EUN HONG ${ }^{2}$, JI-YOUNG KIM ${ }^{1}$, SE-KYEONG JANG ${ }^{2}$, YOUNG-SUN KIM ${ }^{1}$, \\ JU-HEE SIM ${ }^{1}$, AC-CHIN OH ${ }^{3}$, HEYJIN KIM ${ }^{3}$, YOUNG JUN HONG ${ }^{3}$, JIN-KYUNG LEE ${ }^{1,3}$ and IN-CHUL PARK ${ }^{2}$ \\ ${ }^{1}$ KIRAMS Radiation Biobank, Korea Institute of Radiological and Medical Sciences, Seoul, Republic of Korea; \\ ${ }^{2}$ Division of Fusion Radiology Research, Korea Institute of Radiological and Medical Sciences, Seoul, Republic of Korea; \\ ${ }^{3}$ Department of Laboratory Medicine, Korea Institute of Radiological and Medical Sciences, Seoul, Republic of Korea
}

\begin{abstract}
Background/Aim: Phosphoserine aminotransferase 1 (PSAT1) is an enzyme implicated in serine biosynthesis, and its overexpression has been linked to cancer cell proliferation. Therefore, targeting PSAT1 is considered to be an anticancer strategy. Materials and Methods: The viability of non-small cell lung cancer (NSCLC) cells was measured by MTT assay. Protein and mRNA expression were determined by western blot and reverse transcription polymerase chain reaction, respectively. Results: Glutamine-limiting conditions were generated through glutamine deprivation or CB-839 treatment, which induced PSAT1 expression in NSCLC cells. PSAT1 expression induced by glutamine-limiting conditions was regulated by activating transcription factor 4 . Knockdown of PSAT1 enhanced the sensitivity of NSCLC cells to glutamine-limiting conditions. Interestingly, ionizing radiation induced PSAT1 expression, and knocking down PSAT1 increased cell sensitivity to ionizing radiation. Conclusion: Inhibiting PSAT1 might aid in the treatment of lung cancer, and PSAT1 may be a therapeutic target for lung cancer.
\end{abstract}

Metabolic alternation plays a key role in the adaption of cancer cells to a changing extracellular environment. Cancer cells have unique metabolic characteristics, such as elevated energy and biosynthesis as required for rapid cell growth and proliferation $(1,2)$. With a higher metabolic rate and increased proliferation, cancer cells have a high nutrient demand (3). To fulfill the increased nutritional demand, cancer cells usually up-regulate

Correspondence to: Hyeon-Ok Jin, Ph.D., Korea Institute of Radiological and Medical Sciences, 75 Nowon-ro, Nowon-gu, Seoul, 01812, Republic of Korea. Tel: +82 29701692, Fax: +82 29702455, e-mail: hyeonok@kirams.re.kr; In-Chul Park, PhD, Korea Institute of Radiological and Medical Sciences, 75 Nowonro, Nowon-gu, Seoul, 01812, Republic of Korea. Tel: +82 29701378, Fax: +82 29702455, e-mail: parkic@kirams.re.kr

Key Words: Activating transcription factor 4, glutamine, ionizing radiation, non-small cell lung cancer, phosphoserine aminotransferase 1 . their uptake of glucose and glutamine from the extracellular environment. As most glucose is converted into lactate, cancer cells become heavily dependent on glutamine as a major source of carbon and nitrogen (4). Glutamine serves as a source of nitrogen for the synthesis of nucleotides, amino acids and proteins, and it is involved in glutathione production to support antioxidative defense (5). Glutamine also serves as a source of carbon that replenishes tricarboxylic acid cycle intermediates (6). Cancer cells become addicted to glutamine as a consequence of genetic or epigenetic abnormalities. These genetic abnormalities result not only in the import of glutamine via the up-regulation of glutamine transporters but also in the promotion of expression of metabolic enzymes that are involved in the metabolism of glutamine (7). Suppression of glutamine metabolism by depriving cells of glutamine, inhibiting glutaminase or blocking glutamine transporters has been considered an attractive anticancer strategy (8). CB-839 is a potent, selective, reversible and orally bioavailable inhibitor of glutaminase that can inhibit cellular glutamine-to-glutamate metabolism. CB-839 has shown an antitumor effect on triple-negative breast cancer cells and leukemia cells $(9,10)$.

Phosphoserine aminotransferase 1 (PSAT1) is an enzyme implicated in the biosynthesis of the amino acid serine (11). PSAT1 is overexpressed in breast cancer, colon cancer, esophageal squamous cell carcinoma and non-small cell lung cancer (NSCLC), and its increased expression has been shown to enhance cancer cell proliferation, metastasis and chemoresistance (12-16). Thus, targeting PSAT1 is considered to be an anticancer strategy. This study aimed to investigate the role of PSAT1 in resistance under glutaminelimiting conditions in NSCLC cells and the mechanism by which PSAT1 is regulated.

\section{Materials and Methods}

Cell culture and reagents. H1299 and H460 human NSCLC cells were obtained from ATCC (Manassas, VA, USA) and cultured in RPMI 1640 medium (\#LM011-01; Welgene, Gyeongsangbuk-do, Republic of Korea) supplemented with $10 \%$ fetal bovine serum (Gibco; Thermo 
Fisher Scientific, Waltham, MA, USA). For glutamine-free medium, RPMI 1640 without L-glutamine (\#LM011-05; Welgene) was supplemented with $10 \%$ dialyzed fetal bovine serum (Gibco; Thermo Fisher Scientific). CB-839 was purchased from Cayman Chemical (Ann Arbor, MI, USA), and thiazolyl blue tetrazolium bromide (MTT) was purchased from Sigma-Aldrich (Merck KGaA, Darmstadt, Germany). ${ }^{137}$ Cesium was used as a source of gamma radiation (Atomic Energy of Canada Limited, Chalk River, ON, Canada). Protein lysates from normal lung tissue \#1 (\#CP565585), normal lung tissue \#2 (\#CP565577), lung cancer stage IB \#3 (adenocarcinoma, \#CP565638), lung cancer stage IB \#4 (squamous carcinoma, \#CP565643), lung cancer stage IB \#5 (large cell carcinoma, \#CP565586), lung cancer stage IIIA \#6 (adenocarcinoma, \#CP565414), lung cancer stage IIIA \#7 (squamous carcinoma, \#CP565564), and lung cancer stage IIIA \#8 (large cell carcinoma, \#CP565534) were purchased from OriGene Technologies (Rockville, MD, USA). TissueScan Lung Cancer Tissue qPCR panel (Lung Cancer cDNA array II \#HLRT502) was also obtained from OriGene Technologies, and contained cDNA from five normal lungs, 15 stage IA, 10 stage IB, 4 stage IIA, 2 stage IIB, 5 stage IIIA, 5 stage IIIB, and 2 stage IV lung cancer samples.

Measurement of cell viability. H1299 and H460 cells were seeded in a 6-well plate and were grown overnight until they reached about $50 \%$ cell confluence. The cells were exposed to glutamine-free medium or treated with CB-835 $(1,2$ or $5 \mu \mathrm{M})$ for $24 \mathrm{~h}$. Cell viability was assessed by measuring the mitochondrial conversion of MTT. The proportion of converted MTT was calculated by measuring the absorbance at $570 \mathrm{~nm}$. The results are expressed as the percentage reduction in MTT under the assumption that the absorbance of the control cells was $100 \%$. The MTT experiments were repeated three times.

RNA extraction and reverse transcription polymerase chain reaction (RT-PCR). RNA was isolated from H1299 and H460 cells using TRIzol reagent according to the manufacturer's instructions (Invitrogen; Thermo Fisher Scientific). cDNA primed with oligo dT was prepared from $2 \mathrm{mg}$ total RNA using M-MLV reverse transcriptase (Invitrogen; Thermo Fisher Scientific).

The following specific primers were used for PCR: PSAT1: 5'GTCCAGTGGAGCCCCAAAA-3' and 5'-TGCCTCCCACAGA CCTATGC-3',150 bp product (12); $\beta$-Actin (ACTB): 5'GGATTCCTATGTGGGCGACAG-3' and 5'-CGCTCGGTGAGGA TCTTCATG-3', 438 bp product (17). Amplication of PSAT1 was performed for 28 cycles at $95^{\circ} \mathrm{C}$ for $30 \mathrm{~s}, 55^{\circ} \mathrm{C}$ for $30 \mathrm{~s}$ and $72^{\circ} \mathrm{C}$ for $30 \mathrm{~s}$. Amplication of $A C T B$ was performed for 25 cycles at $95^{\circ} \mathrm{C}$ for $30 \mathrm{~s}, 55^{\circ} \mathrm{C}$ for $30 \mathrm{~s}$ and $72^{\circ} \mathrm{C}$ for $30 \mathrm{~s}$. The PCR products were visualized on $2 \%$ agarose gel containing ethidium bromide. The band intensities were quantified using ImageJ software (version 1.52a; NIH; National Institutes of Health, Bethesda, MD, USA).

Transient transfection. The expression plasmid (pEF/mATF4-myc) encoding mouse wild-type activating transcription factor 4 (ATF4) was kindly provided by Dr. Jawed Alam (18). PSAT1 (\#1: 5'CAGGCAAGUUUGAAAUCUdTdT-3', and \#2: 5'-UUCUGACU UGAACUGGAAdTdT-3') small interfering RNAs (siRNAs) were synthesized by Bioneer Corporation (Daejeon, Republic of Korea). ATF4 (\#sc-35112), PSAT1 \#3 (\#sc-92619) and control (\#sc-37007) siRNAs were purchased from Santa Cruz Biotechnology (Dallas, TX, USA). Transfections with plasmids and siRNA in H1299 and
H460 cells were performed using Lipofectamine Plus or Lipofectamine RNAiMAX, respectively, according to the manufacturer's instructions (Invitrogen; Thermo Fisher Scientific). Thirty hours after transfection, the cells were exposed to glutaminefree medium, treated with $5 \mu \mathrm{M}$ CB-839 or exposed to ionizing radiation ( 5 or $10 \mathrm{~Gy}$ ). After 24 or $30 \mathrm{~h}$ of incubation, the cells were harvested for RT-PCR or western blot analysis, and the cell viability was measured by MTT assay.

Western blot analysis. Proteins from cell lysates were separated using $11 \%$ sodium dodecyl sulphate-polyacrylamide gels and transferred to nitrocellulose membranes followed by immunoblotting with the specified primary and horseradish peroxidase-conjugated secondary antibodies. The blots were developed using SuperSignal West Pico Chemiluminescent Substrates (Thermo Scientific Pierce, Rockford, IL, USA) to produce a chemiluminescence signal, which was captured on $\mathrm{X}$-ray film. The following antibodies were used: anti-PSAT1 (\#PA522124) was obtained from Thermo Fisher Scientific, anti-ATF4 (\#sc200) was obtained from Santa Cruz Biotechnology, and anti- $\beta$-Actin (\#A5316) was obtained from Sigma-Aldrich (Merck KGaA).

Statistical analysis. The results are expressed as the mean \pm standard deviation (SD) of three independent experiments. Statistical differences were measured by Student's $t$-test for two groups or a one-way ANOVA for multiple groups, followed by Tukey's test, using GraphPad prism software (version 7.0, San Diego, CA, USA); differences at $p<0.05$ were considered statistically significant.

\section{Results}

Glutamine deprivation or treatment with CB-839, a glutaminase inhibitor, induces PSAT1 expression in NSCLC cells. Firstly, we investigated the effects of glutamine deprivation on the viability of NSCLC cells. H1299 and H460 cells were deprived of glutamine for $24 \mathrm{~h}$, and cell viability was detected by MTT assay. A decrease in cell viability of less than $25 \%$ was observed in both cell lines deprived of glutamine (Figure 1A, left panel). CB-839 is a potent and selective inhibitor of glutaminase, a key enzyme in glutamine metabolism. We observed a decrease in cell viability of less than $20 \%$ when cells from both cell lines were treated with CB-839 at concentrations up to $5 \mu \mathrm{M}$ for $24 \mathrm{~h}$ (Figure $1 \mathrm{~A}$, right panel). Interestingly, PSAT1 protein expression was induced by glutamine deprivation in the H1299 and H460 cells (Figure 1B, left panel). CB-839 also induced PSAT1 protein expression in a dose-dependent manner in both cell lines (Figure 1B, right panel). PSAT1 mRNA expression was increased by glutamine deprivation, and by CB-839 treatment (Figure 1C). These data suggest that glutamine-limiting conditions induce PSAT1 expression in NSCLC cells.

PSAT1 expression under glutamine-limiting conditions is regulated by $A T F 4$. It was reported that glutamine deprivation induces ATF4, which regulates the transcription of genes required for amino acid synthesis and import, redox balance, and angiogenesis, resulting in restoration of homeostasis (19-21). In our study, ATF4 protein expression 
A
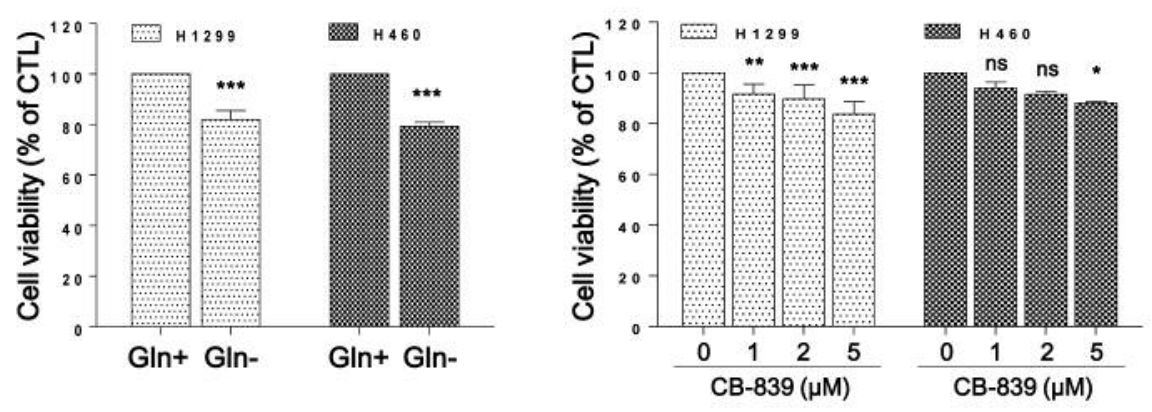

B
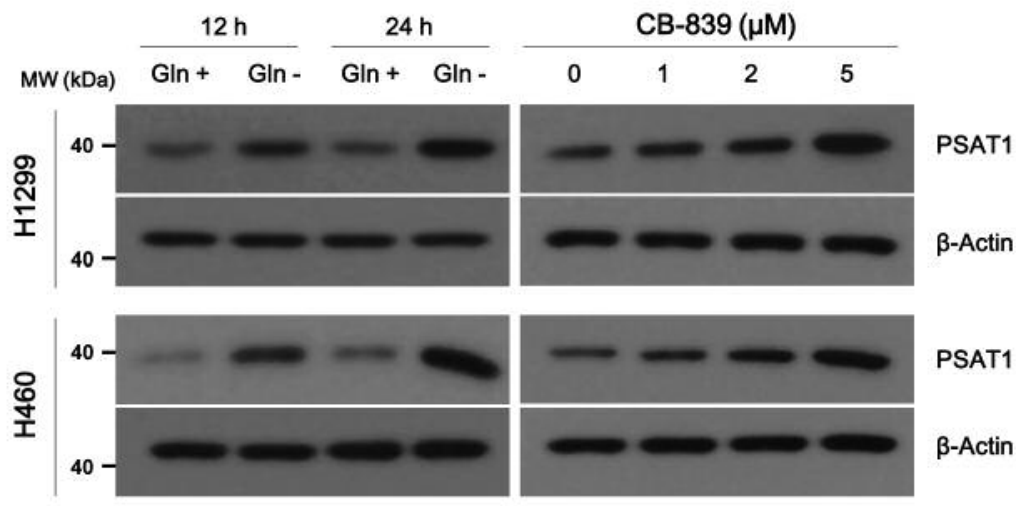

PSAT1

$\beta$-Actin
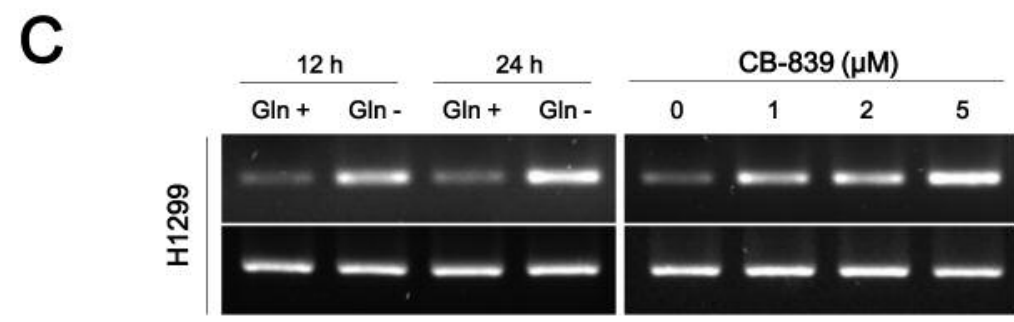

PSAT1
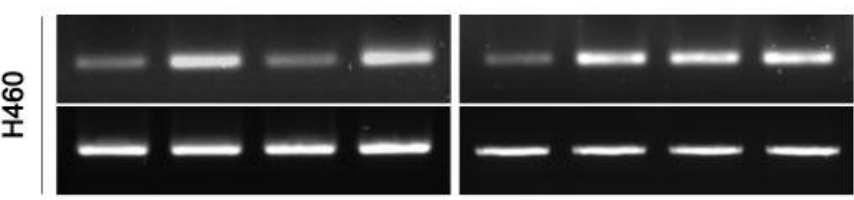

$\beta$-Actin

PSAT1

$\beta$-Actin

Figure 1. Glutamine deprivation or treatment with CB-839, a glutaminase inhibitor, induces phosphoserine aminotransferase 1 (PSAT1) expression in non-small cell lung cancer cells. A: $H 1299$ and $H 460$ cells were grown in glutamine-free medium for 24 h or treated with the indicated concentrations of CB-839 for $24 \mathrm{~h}$. Cell viability was measured by MTT assay. Data are presented as the means $\pm S D$ relative to the control. Significantly different at $* * * p<0.001, * * p<0.01$ or $* p<0.05$ versus the control group; $n s$, not significantly different. B, C: H1299 and H460 cells were grown in glutamine-free medium for 12 or $24 \mathrm{~h}$ or treated with the indicated concentrations of CB-839 for $24 \mathrm{~h}$. The indicated protein (B) and $m R N A(C)$ levels were estimated by western blot and reverse transcription polymerase chain reaction, respectively. The blot is representative of two independent experiments. CTL: Control, Gln: glutamine.

was increased in the H1299 and H460 cells starved of glutamine (Figure 2A, left panel). CB-839 also induced ATF4 expression in both cell lines (Figure 2A, right panel). To investigate whether ATF4 is involved in increasing the expression of PSAT1, we examined PSAT1 expression in H1299 cells transiently transfected with plasmids encoding
Myc-ATF4. Compared with cells transfected with an empty vector, cells that overexpressed Myc-ATF4 exhibited increased levels of PSAT1 mRNA and protein (Figure 2B). We further investigated whether ATF4 is responsible for the up-regulation of PSAT1 expression in response to glutamine deprivation or CB-839. H1299 cells were transfected with 


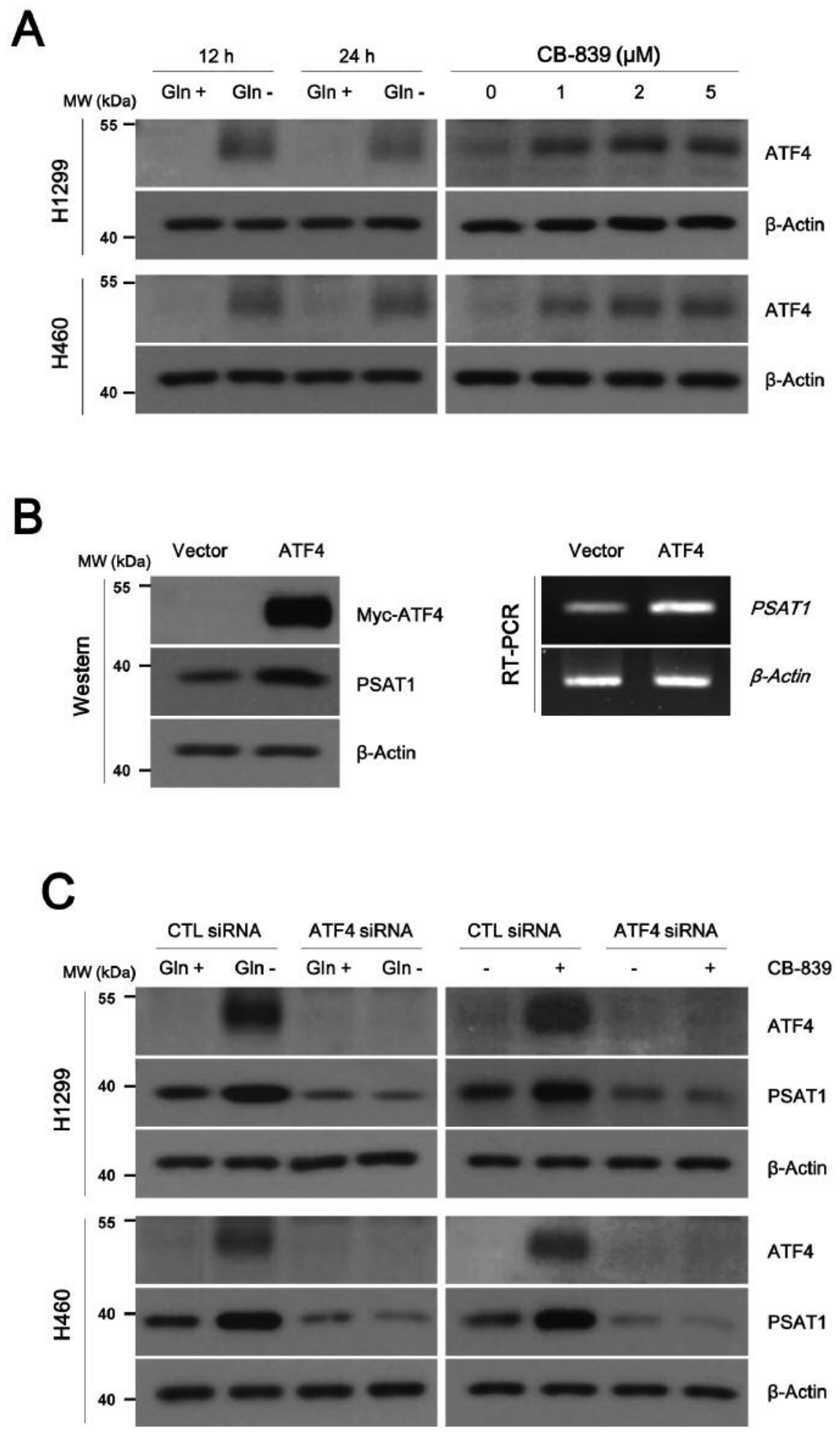

Figure 2. Phosphoserine aminotransferase 1 (PAST1) expression induced by glutamine deprivation or CB-839 treatment is regulated by activating transcription factor 4 (ATF4). A: $H 1299$ and $H 460$ cells were grown in glutamine-free medium for 12 or 24 h or treated with the indicated concentrations of CB-839 for 24 h. B: H1299 cells were transfected with an empty vector or Myc-tagged mATF4 for 30 h. C: H1299 and H460 cells were transfected with control or ATF4 siRNAs for $30 \mathrm{~h}$ and were then exposed to glutamine-free medium for $24 \mathrm{~h}$ or treated with $5 \mu M C B$ 839 for $24 \mathrm{~h}$. The protein and mRNA levels were estimated by western blot and reverse transcription polymerase chain reaction (RT-PCR), respectively. The blot is representative of two independent experiments. CTL: Control. Gln: Glutamine. 
ATF4 siRNA and were deprived of glutamine or treated with CB-839. As shown in Figure 2C, ATF4 siRNA inhibited PSAT1 expression in response to glutamine deprivation and to CB-839. These data suggest that ATF4 activation is important for the induction of PSAT1 expression under glutamine-limiting conditions.

Knocking down PSAT1 enhances cell sensitivity to glutamine deprivation and to CB-839 treatment. PSAT1 has been reported to promote cancer cell proliferation and chemoresistance (14). We investigated whether downregulation of PSAT1 enhanced cell sensitivity to glutamine deprivation or CB-839. H1299 cells were transfected with PSAT1 siRNA and were deprived of glutamine or treated with CB-839. All three PSAT1 siRNAs led to considerable suppression of protein expression (Figure 3A). Suppression of PSAT1 expression with siRNA also significantly reduced the viability of cells deprived of glutamine or treated with CB-839 (Figure 3B and C). These results suggest that knocking down PSATl effectively enhanced cell sensitivity to glutamine-limiting conditions.

PSAT1 is overexpressed in lung cancer tissues and knockdown of PSAT1 increases cell sensitivity to ionizing radiation. It was reported that PSAT1 is closely associated with tumorigenesis in colon and breast cancer, and NSCLC, and that high levels of PSAT1 expression are correlated with poor survival $(16,22,23)$. In our study, PSAT1 protein levels in human lung cancer tissues (stages IB and IIIA) and normal lung tissues were analyzed by western blot analysis A marked increase in PSAT1 protein expression was observed in lung cancer tissues compared with normal lung tissues (Figure 4A). To further evaluate PSAT1 mRNA levels at the different stages of lung cancer, we used a commercially available lung cancer tissue qPCR panel that included cDNAs obtained from 48 patients with histopathologically confirmed lung cancer representing all stages (stage IA, $n=15$; stage IB, $n=10$; stage IIA, $n=4$; stage IIB, $n=2$; stage IIIA, $n=5$; stage IIIB, $n=5$; stage IV, $n=2$ ), and normal lung samples $(n=5)$. In agreement with the protein data, the levels of PSAT1 mRNA were up-regulated in lung cancer tissues compared with normal lung tissues. These data suggested that expression of PSAT1 mRNA and protein is elevated in lung cancer tissue compared with normal lung tissue.

Radiation therapy for treating lung cancer is effective for destroying cancer cells and shrinking tumors (24). Interestingly, ionizing radiation increased PSAT1 protein expression in a dose-dependent manner in H1299 cells (Figure 4C), and silencing PSAT1 with siRNA further reduced the viability of cells exposed to ionizing radiation (Figure 4D). These data suggest that knocking down PSAT1 effectively enhances cell sensitivity to ionizing radiation.

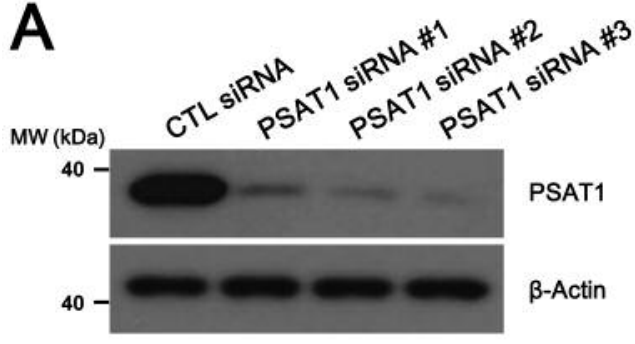

B
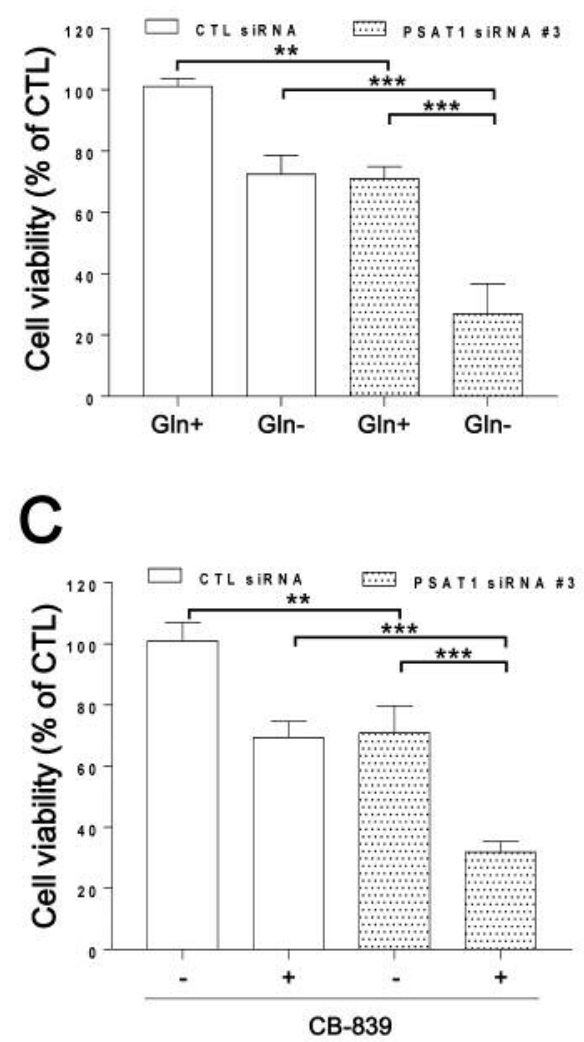

Figure 3. Knocking down phosphoserine aminotransferase 1 (PSAT1) enhances cell sensitivity to glutamine deprivation or CB-839 treatment. A: H1299 cells were transfected with three different PSAT1 siRNAs for $30 \mathrm{~h}$. PSAT1 protein levels were measured using western blot analysis. B, $C$ : H1299 cells were transfected with control or PSAT1 siRNAs for $30 \mathrm{~h}$ and then exposed to glutamine-free medium for $30 h(B)$ or treated with $5 \mu M$ CB-839 for $30 \mathrm{~h}(\mathrm{C})$. Cell viability was measured by MTT assay. CTL: Control, Gln: glutamine. Data are presented as the means $\pm S D$ relative to the control $(n=3)$. Significantly different at $* * p<0.01$ and $* * * p<0.001$.

\section{Discussion}

Glutamine is the most abundant amino acid that participates in energy formation, redox homeostasis, molecular synthesis, and signaling in cancer cells (25). These functions make glutamine metabolism an attractive target 


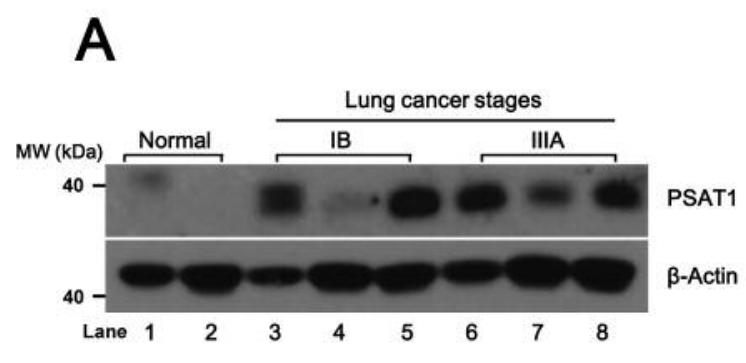

B
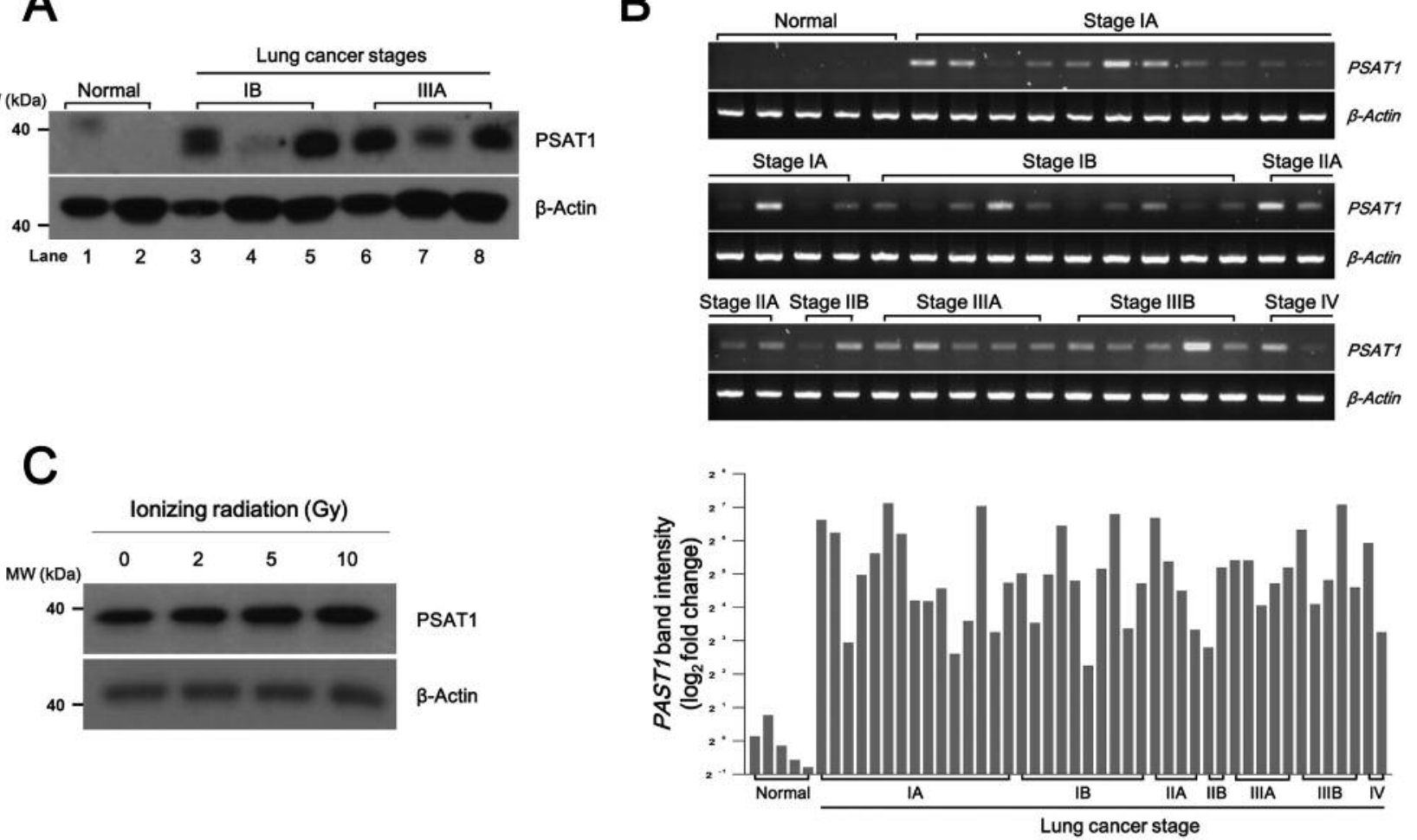

Figure 4. Phosphoserine aminotransferase 1 (PSAT1) is up-regulated in lung cancer tissues, and knocking down PSAT1 enhances cell sensitivity to ionizing radiation. A: PSAT1 protein levels in normal lung tissues and lung cancer tissues were analyzed by western blot analysis. $\beta$-Actin was used as a loading control. Protein lysates from normal lung tissue (lanes 1 and 2), lung cancer stage IB (lane 3, adenocarcinoma; lane 4, squamous carcinoma; lane 5, large cell carcinoma) and lung cancer stage IIIA (lane 6, adenocarcinoma; lane 7, squamous carcinoma; lane 8, large cell carcinoma) were purchased from OriGene Technologies. B: PSAT1 mRNA levels were determined by quantitative polymerase chain reaction in an OriGene cDNA array of normal lung tissue and lung cancer tissue of different pathological grades. The polymerase chain reaction products were visualized on $2 \%$ agarose gel containing ethidium bromide (upper panel). The band intensities were quantified densitometrically by ImageJ software, and the values were normalized against those of $\beta$-Actin expression, and the log 2 fold change data were plotted (bottom panel). C: $H 1299$ cells were exposed to the indicated dose of ionizing radiation for $24 \mathrm{~h}$. PSAT1 protein was analyzed by western blot analysis. D: $H 1299$ cells were transfected with control or PSAT1 siRNAs for $30 \mathrm{~h}$ and were then exposed to the indicated dose of ionizing radiation for $24 \mathrm{~h}$. Cell viability was measured by MTT assay. $C T L$ : Control. Data are presented as the means $\pm S D$ relative to the control $(n=3)$. Significantly different at ${ }^{* *} p<0.01$ and $* * * p<0.001$. (9, 26-28). Interestingly, we revealed that glutaminelimiting conditions generated by glutamine deprivation or treatment with the glutaminase inhibitor CB-839 induced PSAT1 expression (Figure 1B and C). PSAT1 regulates serine biosynthesis from intermediates generated in the glycolytic pathway. PSAT1 is overexpressed in breast cancer, colon cancer, esophageal squamous cell carcinoma and NSCLC $(12-14,16)$. In the present study, in contrast to the relatively low PSAT1 protein expression in normal lung

tissues, high levels of PSAT1 protein were detected in lung cancer tissues (Figure 4A). In agreement with the protein data, results from the qPCR analysis of human lung cancer tissue cDNA arrays demonstrated that PSAT1 mRNA was up-regulated in the lung cancer tissue compared with 
normal lung tissue. The overexpression of PSAT1 is associated with cell proliferation and chemoresistance in colon cancer (14). The depletion of PSAT1 reduced cell proliferation in breast cancer and $\operatorname{NSCLC}(12,16)$. In our study, knocking down PSAT1 reduced the viability of NSCLC cells and enhanced their sensitivity to glutaminelimiting conditions created through glutamine deprivation or CB-839 treatment.

In response to glutamine deprivation, cancer cells can activate different adaptive responses to restore homeostasis (5). ATF4 expression is increased by glutamine deprivation and promotes transcription of genes required for amino acid synthesis and import, redox balance, and angiogenesis (1921). In our study, ATF4 expression was increased under glutamine-limiting conditions created through glutamine deprivation or CB-839 treatment in NSCLC cells (Figure 2A). Overexpression of ATF4 increased PSAT1 expression, whereas knocking down ATF4 expression with siRNA was capable of diminishing PSAT1 expression under glutamine limiting conditions (Figure 2B and C).

Radiation therapy for lung cancer is effective for destroying cancer cells and shrinking tumors (24). Interestingly, ionizing radiation increased PSAT1 protein expression, and knocking down PSAT1 expression effectively enhanced NSCLC cell sensitivity to ionizing radiation (Figure 4C and D).

These data suggest that inhibiting PSAT1 might aid in the treatment of lung cancer and that PSAT1 may be a therapeutic target for lung cancer therapy.

\section{Conflicts of Interest}

The Authors declare no conflicts of interest regarding this study.

\section{Authors' Contributions}

Hyeon-Ok Jin and In-Chul Park developed the concept and designed the study. Hyeon-Ok Jin, Sung-Eun Hong, Ji-Young Kim, Se-Kyung Jang, Young-Sun Kim and Ju-Hee Sim carried out the experiments. Ac-Chin Oh, HeyJin Kim, Young Jun Hong and Jin-Kyung Lee provided technical support and conceptual advice. Hyeon-Ok Jin and In-Chul Park wrote the article. All Authors read and approved the final article.

\section{Acknowledgements}

The present study was supported by grants from the Basic Science Research Program through the National Research Foundation of Korea (NRF) funded by the Ministry of Education (NRF-2017R1D1A1B03029209/50604-2019), the Mid-Career Researchers Program through the NRF funded by the Ministry of Science and ICT (MIST) (NRF-2017R1A2B2008398/506492019) and the Korea Institute of Radiological and Medical Sciences (KIRAMS) funded by the MIST (50544-2019), Republic of Korea.

\section{References}

1 DeBerardinis RJ, Lum JJ, Hatzivassiliou G and Thompson CB: The biology of cancer: Metabolic reprogramming fuels cell growth and proliferation. Cell Metab 7: 11-20, 2008. PMID: 18177721. DOI: $10.1016 /$ j.cmet.2007.10.002

2 Dang CV: Links between metabolism and cancer. Genes Dev 26: 877-890, 2012. PMID: 22549953. DOI: 10.1101/gad.189365.112

3 Ward PS and Thompson CB: Metabolic reprogramming: A cancer hallmark even warburg did not anticipate. Cancer Cell 21: 297-308, 2012. PMID: 22439925. DOI: 10.1016/ j.ccr.2012.02.014

4 Wise DR and Thompson CB: Glutamine addiction: A new therapeutic target in cancer. Trends Biochem Sci 35: 427-433, 2010. PMID: 20570523. DOI: 10.1016/j.tibs.2010.05.003

5 Altman BJ, Stine ZE and Dang CV: From Krebs to clinic: Glutamine metabolism to cancer therapy. Nat Rev Cancer 16: 619-634, 2016. PMID: 27492215. DOI: 10.1038/nrc.2016.71

6 Le A, Lane AN, Hamaker M, Bose S, Gouw A, Barbi J, Tsukamoto T, Rojas CJ, Slusher BS, Zhang H, Zimmerman LJ, Liebler DC, Slebos RJ, Lorkiewicz PK, Higashi RM, Fan TW and Dang CV: Glucose-independent glutamine metabolism via TCA cycling for proliferation and survival in B-cells. Cell Metab 15: 110-121, 2012. PMID: 22225880. DOI: 10.1016/j.cmet.2011.12.009

7 Tardito S, Oudin A, Ahmed SU, Fack F, Keunen O, Zheng L, Miletic H, Sakariassen PO, Weinstock A, Wagner A, Lindsay SL, Hock AK, Barnett SC, Ruppin E, Morkve SH, Lund-Johansen M, Chalmers AJ, Bjerkvig R, Niclou SP and Gottlieb E: Glutamine synthetase activity fuels nucleotide biosynthesis and supports growth of glutamine-restricted glioblastoma. Nat Cell Biol 17: 1556-1568, 2015. PMID: 26595383. DOI: $10.1038 / \mathrm{ncb} 3272$

8 Chen L and Cui H: Targeting glutamine induces apoptosis: A cancer therapy approach. Int J Mol Sci 16: 22830-22855, 2015. PMID: 26402672. DOI: 10.3390/ijms 160922830

9 Gross MI, Demo SD, Dennison JB, Chen L, Chernov-Rogan T, Goyal B, Janes JR, Laidig GJ, Lewis ER, Li J, Mackinnon AL, Parlati F, Rodriguez ML, Shwonek PJ, Sjogren EB, Stanton TF, Wang T, Yang J, Zhao F and Bennett MK: Antitumor activity of the glutaminase inhibitor $\mathrm{CB}-839$ in triple-negative breast cancer. Mol Cancer Ther 13: 890-901, 2014. PMID: 24523301. DOI: 10.1158/1535-7163.MCT-13-0870

10 Jacque N, Ronchetti AM, Larrue C, Meunier G, Birsen R, Willems L, Saland E, Decroocq J, Maciel TT, Lambert M, Poulain L, Hospital MA, Sujobert P, Joseph L, Chapuis N, Lacombe C, Moura IC, Demo S, Sarry JE, Recher C, Mayeux P, Tamburini $\mathbf{J}$ and Bouscary D: Targeting glutaminolysis has antileukemic activity in acute myeloid leukemia and synergizes with BCL-2 inhibition. Blood 126: 1346-1356, 2015. PMID: 26186940. DOI: 10.1182/blood-2015-01-621870

11 Liao KM, Chao TB, Tian YF, Lin CY, Lee SW, Chuang HY, Chan TC, Chen TJ, Hsing $\mathrm{CH}$, Sheu MJ and $\mathrm{Li} \mathrm{CF}$ : Overexpression of the PSAT1 gene in nasopharyngeal carcinoma is an indicator of poor prognosis. J Cancer 7: 1088-1094, 2016. PMID: 27326252. DOI: 10.7150/jca.15258

12 Gao S, Ge A, Xu S, You Z, Ning S, Zhao Y and Pang D: PSAT1 is regulated by ATF4 and enhances cell proliferation via the GSK3 $\beta / \beta$-catenin/cyclin D1 signaling pathway in ER-negative breast cancer. J Exp Clin Cancer Res 36: 179, 2017. PMID: 29216929. DOI: 10.1186/s13046-017-0648-4. 
13 Liu B, Jia Y, Cao Y, Wu S, Jiang H, Sun X, Ma J, Yin X, Mao $A$ and Shang $\mathrm{M}$ : Overexpression of phosphoserine aminotransferase 1 (PSAT1) predicts poor prognosis and associates with tumor progression in human esophageal squamous cell carcinoma. Cell Physiol Biochem 39: 395-406, 2016. PMID: 27372650. DOI: 10.1159/000445633

14 Vie N, Copois V, Bascoul-Mollevi C, Denis V, Bec N, Robert B, Fraslon C, Conseiller E, Molina F, Larroque C, Martineau P, Del Rio $\mathrm{M}$ and Gongora $\mathrm{C}$ : Overexpression of phosphoserine aminotransferase PSAT1 stimulates cell growth and increases chemoresistance of colon cancer cells. Mol Cancer 7: 14, 2008. PMID: 18221502. DOI: 10.1186/1476-4598-7-14

15 Pollari S, Kakonen SM, Edgren H, Wolf M, Kohonen P, Sara H, Guise $T$, Nees $M$ and Kallioniemi O: Enhanced serine production by bone metastatic breast cancer cells stimulates osteoclastogenesis. Breast Cancer Res Treat 125: 421-430, 2011. PMID: 20352489. DOI: 10.1007/s10549-010-0848-5

16 Yang Y, Wu J, Cai J, He Z, Yuan J, Zhu X, Li Y, Li M and Guan $\mathrm{H}$ : PSAT1 regulates cyclin D1 degradation and sustains proliferation of non-small cell lung cancer cells. Int J Cancer 136: E39-50, 2015. PMID: 25142862. DOI: 10.1002/ijc.29150

17 Jin HO, Park IC, An S, Lee HC, Woo SH, Hong YJ, Lee SJ, Park MJ, Yoo DH, Rhee $\mathrm{CH}$ and Hong SI: Up-regulation of BAK and BIM via JNK downstream pathway in the response to nitric oxide in human glioblastoma cells. J Cell Physiol 206: 477-486, 2006. PMID: 16158421. DOI: 10.1002/jcp.20488

$18 \mathrm{He} \mathrm{CH}$, Gong P, Hu B, Stewart D, Choi ME, Choi AM and Alam J: I Identification of activating transcription factor 4 (ATF4) as an NRF2-interacting protein. Implication for heme oxygenase-1 gene regulation. J Biol Chem 276: 20858-20865, 2001. PMID: 11274184. DOI: 10.1074/jbc.M101198200

19 Chen R, Zou Y, Mao D, Sun D, Gao G, Shi J, Liu X, Zhu C, Yang M, Ye W, Hao Q, Li R and Yu L: The general amino acid control pathway regulates mTOR and autophagy during serum/glutamine starvation. J Cell Biol 206: 173-182, 2014. PMID: 25049270. DOI: 10.1083/jcb.201403009

20 Harding HP, Zhang Y, Zeng H, Novoa I, Lu PD, Calfon M, Sadri N, Yun C, Popko B, Paules R, Stojdl DF, Bell JC, Hettmann T, Leiden JM and Ron D: An integrated stress response regulates amino acid metabolism and resistance to oxidative stress. Mol Cell 11: 619-633, 2003. PMID: 12667446. DOI: 10.1016/s10972765(03)00105-9

21 Kilberg MS, Pan YX, Chen H and Leung-Pineda V: Nutritional control of gene expression: How mammalian cells respond to amino acid limitation. Annu Rev Nutr 25: 59-85, 2005. PMID: 16011459. DOI: 10.1146/annurev.nutr.24.012003.132145
22 Friederichs J, Rosenberg R, Mages J, Janssen KP, Maeckl C, Nekarda H, Holzmann B and Siewert JR: Gene expression profiles of different clinical stages of colorectal carcinoma: Toward a molecular genetic understanding of tumor progression. Int J Colorectal Dis 20: 391-402, 2005. PMID: 15883783. DOI: 10.1007/s00384-004-0722-1

23 Martens JW, Nimmrich I, Koenig T, Look MP, Harbeck N, Model F, Kluth A, Bolt-de Vries J, Sieuwerts AM, Portengen H, Meijer-Van Gelder ME, Piepenbrock C, Olek A, Hofler H, Kiechle M, Klijn JG, Schmitt M, Maier S and Foekens JA: Association of DNA methylation of phosphoserine aminotransferase with response to endocrine therapy in patients with recurrent breast cancer. Cancer Res 65: 4101-4117, 2005. PMID: 15899800. DOI: 10.1158/0008-5472.CAN-05-0064

24 Baskar R, Lee KA, Yeo R and Yeoh KW: Cancer and radiation therapy: Current advances and future directions. Int J Med Sci 9: 193-199, 2012. PMID: 22408567. DOI: 10.7150/ijms.3635

25 Hensley CT, Wasti AT and DeBerardinis RJ: Glutamine and cancer: Cell biology, physiology, and clinical opportunities. J Clin Invest 123: 3678-3684, 2013. PMID: 23999442. DOI: 10.1172/JCI69600

26 Chiu M, Tardito S, Pillozzi S, Arcangeli A, Armento A, Uggeri J, Missale G, Bianchi MG, Barilli A, Dall'Asta V, Campanini N, Silini EM, Fuchs J, Armeanu-Ebinger $S$ and Bussolati O: Glutamine depletion by crisantaspase hinders the growth of human hepatocellular carcinoma xenografts. Br J Cancer 111: 1159-1167, 2014. PMID: 25072259. DOI: 10.1038/bjc.2014.425

27 Hassanein M, Hoeksema MD, Shiota M, Qian J, Harris BK, Chen H, Clark JE, Alborn WE, Eisenberg R and Massion PP: SLC1A5 mediates glutamine transport required for lung cancer cell growth and survival. Clin Cancer Res 19: 560-570, 2013. PMID: 23213057. DOI: 10.1158/1078-0432.CCR-12-2334

28 Lee YZ, Yang CW, Chang HY, Hsu HY, Chen IS, Chang HS, Lee CH, Lee JC, Kumar CR, Qiu YQ, Chao YS and Lee SJ: Discovery of selective inhibitors of glutaminase-2, which inhibit mTORC1, activate autophagy and inhibit proliferation in cancer cells. Oncotarget 5: 6087-6101, 2014. PMID: 25026281. DOI: 10.18632 /oncotarget 2173
Received November 11, 2019

Revised November 16, 2019

Accepted November 18, 2019 